\title{
The Application of POA (Production-oriented Approach) in the Course of English Viewing, Listening \& Speaking for English Majors
}

\begin{abstract}
Han Li
School of Foreign Languages, Chengdu Normal University, Chengdu, China 11080601@qq.com

ABSTRACT

For a long time, the Listening and Speaking courses for English majors have been set separately. Based on POA, the author's department has tried to combine speaking with listening, changing traditional Listening course into English Viewing, Listening \& Speaking course. Choosing Unit 4 "Flying In and Out" of Listen This Way 1, the author carried out experiment of POA in two classes in which the levels of students were same. After that, the author reflected and did the questionnaire and interview to get POA is applicable and effective in combining speaking with listening, but there are still some problems to be solved, such as, challenges for teachers to design tasks for different levels of students and be a good facilitator.
\end{abstract}

Keywords: POA, The Course of English Viewing, Listening \& Speaking, English Majors

\section{INTRODUCTION}

POA (production-oriented approach) is a teaching theory with Chinese characteristics put forward by Prof. Wen Qiufang's team, which consists of three parts, teaching idea, teaching hypothesis, and teaching procedures, with its fundamental objective to solve the current situation of separation of learning and using language. And the chief teaching procedure is the mode of "motivating-enabling-assessing" built both by teachers and students and lead by teachers. The course of English Viewing, Listening \& Speaking in the application-oriented university the author worked experienced changes. Before 2019, the course was named English Listening, with the traditional teaching mode "listening-checking answers-listening again". After 2019, based on Undergraduate Teaching Guide for English Majors, the courses were named English Viewing, Listening \& Speaking, but the teaching mode has not changed a lot. According to the interviews of students in the past three years, it is found that the overall atmosphere of the course was dull with low participation of students and low efficiency of class. Therefore, the author uses POA to carry out a teaching experiment for one semester to change the traditional teaching mode.

\section{THE TEACHING EXPERIMENT OF ENGLISH VIEWING, LISTENING \& SPEAKING BASED ON POA}

\subsection{Purpose}

To evaluate the effectiveness of POA in the course of English Viewing, Listening \& Speaking for English Majors.

\subsection{Contents}

The $3^{\text {rd }}$ edition of Listen This Way is selected for this course in the author's university. And the textbook contains 11 units in total. Except the $11^{\text {th }}$ unit, a review unit, each of the first 10 units revolve around a topic of society and life. The author chooses Unit 4 Flying In and Out in Volume 1 to elaborate on the procedure, the topic of which is relevant to flying, involving small topics like airport announcement and air service.

\subsection{The Procedures}

\subsubsection{Motivating}

"How many of you have flied overseas?" After the teacher asked, only 2 students shared their experience of 
flying abroad, so most of the students have no foreign flying experience. However, there are great opportunities for students to work and study overseas in future, and learning airport dialogues and formalities is applicable and necessary. The step of motivating in POA tries to present students with the situations and topics they are likely to encounter in their future study and work.[1] Thus, they can feel challenges in these situations and topics.

Then, the teacher designed a situation: suppose your friend Mike in the UK will fly to Italy. And this will be his first time to take a plane. Make up a conversation to teach him the process of boarding and getting out of the airport. And students (two students a group) have 5 minutes to prepare for the dialogue, during the process of which the teacher was monitoring their conversations by audio device and walking around the classroom. 5 minutes later, two groups of students were invited to make a performance. A group failed to mention the boarding process, and made a lot of language mistakes. The other group mentioned two steps of boarding process, but still paused a lot. After each group's performance, another student was invited to retell their conversations, but the two students didn't retell them clearly. Up to then, students felt stressed but motivated to fulfil the task well. During the whole process, the teacher wrote down the processes, and language points presented by the two groups on the white board, which were needed to be improved later.

Next, the teacher specified the teaching goals and production task. One type of teaching goals is communication goal, that is, accomplishing certain communication tasks; and the other one is language goal, focusing on grasping some related words, phrases and grammar. And the language goal should serve the communication goal.[2] In this unit, the teaching goals are as follows:

Table 1. Teaching goals

\begin{tabular}{|c|c|}
\hline Structure goal & $\begin{array}{c}\text { Let Students master the } \\
\text { processes of boarding } \\
\text { and getting out of the } \\
\text { airport }\end{array}$ \\
\hline Language goal & $\begin{array}{c}\text { Let Students have a good } \\
\text { grip of about 15 words, 10 } \\
\text { phrases and 5 sentence } \\
\text { patterns }\end{array}$ \\
\hline
\end{tabular}

\subsubsection{Enabling}

During this stage, to be the intermediary, the teacher guided the students to choose the proper and related materials on this topic. As mentioned above, students should accomplish structure goal and language goal.
And three steps were needed here, that is, the teacher described the production task first; students carried on their selective study, and the teacher guided them and checked; then, students practiced their production, and the teacher guided them and checked.[3] The concrete steps were as follows.

Before playing the video for the first time, the teacher raised a question: "what are the processes of boarding and getting out of the airport?", which aroused students' attention to appropriate procedures. And students were asked to pay attention to the differences between the processes in the video and their own processes prepared in the motivating stage. Before playing the video for the second time, the teacher led students to focus on the words, phrases and sentence patterns in the video. Then, the teacher and students discussed the difficult points students encountered.

After the third time, several students were invited to retell the process, and summarize the language points. And the teacher introduced some background information about the topic. At last, students were invited to sum up the processes of boarding and getting out of the airport. When they retold and summed up the tasks, the teacher made the immediate assessing.

Therefore, through the above enabling, the teacher and students changed the traditional way of listening and checking answers, because students can find their problems while watching the video, and the teacher can help students think by providing right materials and discussing with them.

\subsubsection{Assessing}

The step of assessing is to evaluate students' productions, which reflect the teacher's teaching effect; at the same time, students can know their own learning to further improve their production quality. [4]

Two students a group prepared the conversation again. The teacher also monitored all students by the audio device. After 5 minutes, two groups were invited to present their dialogues. They spoke fluently and the processes they presented were much more complete than those in the motivating stage. As for the boarding process, the two groups mentioned "check in", "security check", "passport check"; and "passport check". "Baggage claim" and "transfer" were mentioned in the process of getting out of the airport. And they could use expressions like "boarding bridge", "carry-on bags", and "scanner". When they completed their conversations, two students were invited to comment on their dialogues. One student said the "customs check" wasn't mentioned, and the other student compared his own conversation with those of the two groups. In the end, the teacher assessed the whole process, while approving all students' performance, she corrected the mistakes students made. 


\section{TEACHING FEEDBACK}

During the teaching process, the teacher collected the experiment data through recording, questionnaire, students' and other teachers' interviews. All the students were asked to note down anything about this teaching mode, including advantages and disadvantages, and 55 valid questionnaires were collected, which were encoded. Then, four groups of students who had performed were invited to give their feelings and answer important questions. After that, the teacher's colleagues who taught the same course were interviewed. The results are as follows:

\subsection{Students' high engagement to facilitate the active learning}

In traditional way of "listening-checking answers-listening again", students seldom had opportunities to participate in class, in which most students were absent-minded and reluctant to think. Thus, the atmosphere was not active with few student-teacher interactions. However, when the teacher changed the teaching mode, most students would like to speak up. In the motivating stage, almost all the students took part in the activities actively, because they will encounter this situation in future. In the enabling stage, students made great efforts to think under the guidance of the teacher. And in the assessing stage, there were many interactions between students and the teacher, and also among students. Some students' questionnaires were selected here:

S1: I feel this form made me participate more, which drove me to experience the contents in a deep way and understand details all the more.

S5: We were discussing the topic in real situation. Then, we made performance, and after the video, we clearly knew what we lacked. Through the process, we had deeper impression on difficult points.

S11: This form made the atmosphere more active, at the same time, we have the chance to improve our oral English and learn to cooperate with other classmates.

S20: This form forced us all to take part in the whole process.

S32: "Learning by doing", I not only actively participated in class, but also found some useful points I didn't notice before.

\subsection{Clear learning objectives to increase the production}

In the traditional way, students only had the listening training, and they should do different kinds of listening exercises on one certain topic. Thus, most of them were not interested in the contents. They had no clear objectives, and did not know what abilities they should improve. And they only followed the fixed mode to finish the exercise. But there was a real situation created in the motivating stage in POA, which aroused students' interest. The following are some students' questionnaires:

S54: The situation is real and useful. Although I am an English major, I prefer to look at Chinese signs in the airport instead of English signs. Therefore, I will keep my eyes open to the real-life situation.

S50: It is significant to have simulated the boarding process. I clearly knew the target of this unit, and tried my best to learn the topic, including the structure and the language points.

S48: I thought group discussion made target clearer.

S45: In the traditional way, I cannot be quite familiar with the boarding process.

S38: This form helped me set my goal of learning the process of taking a plane.

In the past, there were few students' oral productions, because most exercises were listening exercises. Even if there were oral practice related to listening, most students couldn't express well. However, different from the traditional way, three stages of POA requires students' production, and their productions were improved in the later stage. After the whole process, students' productions improved a lot.

Group 1 and Group 2 performed in the motivating stage, and Group 3 and Group 4 performed in the assessing stage.

Table 2. The comparisons of productions

\begin{tabular}{|c|c|c|}
\hline Group & $\begin{array}{c}\text { The targeted } \\
\text { structure } \\
\text { (boarding } \\
\text { process and the } \\
\text { process of } \\
\text { getting out of } \\
\text { the airport) }\end{array}$ & $\begin{array}{c}\text { The targeted } \\
\text { language } \\
\text { (words, phrases, } \\
\text { sentence } \\
\text { patterns) }\end{array}$ \\
\hline 1 & 0 & 4 \\
\hline 2 & 2 & 6 \\
\hline 3 & 6 & 10 \\
\hline 4 & 6 & 12 \\
\hline
\end{tabular}

From the above chart, it can be seen that the productions of Group 3 and Group 4 were much better than those of Group 1 and Group 2. When interviewed, all of the eight students said at the beginning, they hardly knew the steps in the airport and they cannot accurately express themselves. But they said, after the enabling stage, they were confident enough to accomplish the conversations. Other students had the same feelings: 
S35: During the whole process, I thought, learned, and improved a lot, and the last conversation gave me a sense of accomplishment.

S28: This form is amazing; I can express myself after the whole process although I failed to do in the first stage.

S15: I like this teaching mode, and I can learn more in such an interesting situation.

\subsection{Multiple assessing applied to enhance learning}

Different from the traditional way, teacher-student collaborative assessing was used in POA. In the traditional way, only the teacher had the right to assess the students' performance. However, production is the key to POA, thus, the effective and timely assessments to students' productions are of vital importance. Wen Qiufang created the Teacher-Student Collaborative Assessment.[5] Every task involved the following steps: students' independent thinking, group discussion, communication led by the teacher, and the teacher's assessing. The advantages of TSCA are obvious, firstly, the teacher chooses the key and difficult points to assess, which improves the efficiency of assessment; secondly, students compare and choose different ways by discussion and communication, which makes them have better productions. And at times, students' modified versions may be better than those of the teacher, which improves both teaching and learning. And the effects can be reflected from the following students' responses.

S30: I practiced my expressing and logic abilities through assessing.

S33: Through group discussion, I would not be absent-minded. And most important of all, I was corrected by classmates and the teacher, which made me understand the difficult points better.

S40: The assessing drove us to involve actively, which consolidated our memories.

S22: I think the group of two students can make us acquire more knowledge, which can't be got on one's own.

S8: All the students participated in the whole process, preparing, performing, and assessing, which forced students not only to listen to other students' and the teacher's comments.

\subsection{Suggestions}

As a whole, the new method brought about good teaching and learning effects, which were recognized by colleagues and students. However, some suggestions were put forward to improve the method.

\subsubsection{Adjusting time to better fulfil the task}

The time used to play the video once was about 5 minutes, and a total of 15-20 minutes were used to play three to four times. After each time, several minutes were used for students' discussion and students and the teacher's assessment. Thus, almost one period of class time was used.

S9: It is unrealistic to carry out class activities like this way, which will slow down the teaching schedule. And I think the teacher would choose the proper units to conduct the activities.

S40: However, it would take a long time to fulfil the task.

Several students suggested that the topic should be assigned before class to save time in class, and at the same time, students can have more time to prepare the related expressions.

The teacher's colleagues also pointed out that plenty of time was used in the motivating and enabling stage, which should be allotted for students' production.

\subsubsection{More attention should be paid to the listening part}

Although students' production quality improved little by little during the whole process, some students still felt difficult in listening. Students used a lot of time to prepare the oral performance, neglecting the listening.

S15: The time used for listening and practicing listening was little.

S23: The video chosen should be without any subtitles for us better to practice listening.

\section{REFLECTIONS}

Through one-semester practice, the author had certain understanding of the advantages and difficulties of POA.

\subsection{Advantages}

To begin with, students' enthusiasm would be motivated and the role of the teacher would be changed into facilitator. The task set at the beginning aroused students' enthusiasm. Students felt it was useful, and they were fully involved in it. Students used the words like "interesting", and "fantastic" to express their feelings. Meanwhile, the teacher enabled students to learn, reducing students' anxieties. Therefore, active emotional experience is vital to POA.

What's more, students have more opportunities to use language and their production quality improved a lot. The teacher designed the task, and provided the video and language materials. Students learned in a selective 
and active way, which made the receptive knowledge to change into productive knowledge.[6]

\subsection{Difficulties}

On the one hand, as POA requires students to actively take part in the activities, it is difficult for students with poor English foundation. Some students didn't say anything in class, and one fourth of all students said that they preferred the traditional way, which reflected that some students got used to learning English in a passive way. Thus, it is a challenge for the teacher to choose and design the proper tasks for students. Tasks should not be too difficult for most students to finish while they should be closely related to the provided materials. Therefore, the task and the enabling materials should be in line with the students' Zone of Proximal Development, and they should also be based on the law of students' language abilities, emotional and cognitive development.

On the other hand, another difficult point for the teacher is that the teacher tended to neglect his or her role to be the facilitator to let students themselves control the class. In this situation, students use a lot of time to discuss topics, and they cannot be promptly guided by the teacher, thus, reducing the efficiency of language learning. With the deepening of teaching and the development of students' ability, the teacher's intervention should be gradually reduced so that the students' active learning can be brought into play.

\section{CONCLUSION}

POA is a new teaching method native in China. From the above teaching case, it can be seen that this method is applicable and effective in the course of English Viewing, Listening \& Speaking for English majors. However, I am in the stage of learning this method, and the teaching experiment was not long, therefore, the advantages and difficulties may be more than those mentioned above. In later teaching, I would learn and practice more about POA to well apply the theory into teaching and better promote students' learning.

\section{Fund Project}

"Research on the Teaching Mode and Assessing System of Core Courses for English Majors: A Case Study of the Course English Viewing, Listening \& Speaking" (Grant No. 2020JG30) at 2020 Chengdu Normal University's Teaching Reform Project

\section{REFERENCES}

[1] Wang Dandan, 2019. Applying Production-oriented Approach to college Indonesian listening and speaking class: A teaching research $[\mathrm{J}]$. Foreign
Language Education in China (02),57.

[2] Wen, Qiufang, 2015. Constructing the Theoretical System of POA [J]. Foreign Language Teaching and Research 47: 554.

[3] Qiu Lin, 2017. The step -by -step design of language activities in the production-oriented approach[J]. Modern Foreign Languages (03), 391-392.

[4] Sun Shuguang, 2017. Teacher-student collaborative assessment in classroom teaching: A reflective practice [J]. Modern Foreign Languages (3): 397-406.

[5] Wen, Qiufang, 2016. "Teacher-Student Collaborative Assessment": A new method of assessment proposed by POA[J]. Foreign Language World (5): 37-43.

[6]Zhang Wenjuan, $2016 . \quad$ "Applying Production-oriented Approach to College English Classrooms: A Teaching Experiment" [J]. Foreign Languages and Their Teaching (2):112. 